\title{
The relationship between upper extremity pain and ultrasound use in perinatologist
}

\author{
Ali Erkan Yenigül ${ }^{1} \oplus$, Fedi Ercan²® \\ ${ }^{1}$ Department of orthopedics and traumatology, Uludăg University School of Medicine, Bursa, Turkey \\ ${ }^{2}$ Department of Obstetrics and Gynecology, Division of Perinatology, Konya City Hospital, Konya, Turkey
}

\begin{abstract}
Objectives: To examine the relationship between upper extremity problems and the performance of abdominal sonography to provide an understanding of the prevalence of upper extremity pain among perinatologist.

Methods: This study was conducted as a prospective trial between June-August 2020. The online questionnaire prepared by the researchers was completed by volunteer perinatologists. It included topics such as age, gender, years of perinatology specialist experience, average number of patients per week, minutes each patient's examination lasted and other demographic data is performed. Perinatologists with upper extremity pain were assigned to group 1. Group 2 comprised those who had no upper extremity pain. Patients in group 1 were divided into two subgroups according to pain intensity. All data were compared between groups.

Results: Overall, 115 perinatologists participated in this research. Of all participants, 82 (71.3\%) had upper extremity pain, and $33(28.7 \%)$ had no upper extremity pain. No significant relationship was observed for age, gender, average number of ultrasound examinations per day, or time allotted for each patient's examination between group 1 and 2. Providers performed perinatology services for 5 years (range: 1-23 years) in subgroup $1 \mathrm{~A}$ and for 7 years (range: $1-23$ years) in subgroup 1B $(p=0.02)$.

Conclusions: Upper extremity pain caused by intensive ultrasound use is common in perinatologists; as the years in the profession increase, the frequency and severity of these pains may increase.

Keywords: Upper extremity, pain, ultrasound, perinatologist
\end{abstract}

$\mathbf{M}$ usculoskeletal diseases are important causes of morbidity and disability, and the treatment of these diseases represents one of the most important health challenges in the world $[1,2]$. In particular, upper extremity pain (at the shoulder, arm, elbow, forearm, wrist, and hand) frequently develops, especially in some professions and office environments [3]. In recent years, publications have increasingly shown that high job stress and demands are positively associated with symptoms and disorders in all upper extremity regions $[4,5]$. When we look at the literature, work-related musculoskeletal disorders, overuse syndrome, work-related upper extremity disorders (WRULD), repetitive strain injuries (RSI), musculoskeletal injury (MSI), and cumulative trauma disorder (CTD) are common terms [6]. Pain due to use relates to several risk factors, including medical conditions, biomechanical exposures, work organization factors, work demands, and individual psychosocial variables [7].

In the United States, $81 \%$ of sonographers have scanned in pain for half of their careers, and $20 \%$ of

2 How to cite this article: Yenigül AE, Ercan F. The relationship between upper extremity pain and ultrasound use in perinatologist. Eur Res $J$ 2022;8(2):282-289. DOI: 10.18621/eurj.1030750

Address for correspondence: Ali Erkan Yenigül, MD., Uludağ University School of Medicine, Department of Orthopedics and Traumatology, Görükle, Bursa, Turke.E-mail: alierkanyenigul@hotmail.com, GSM: +90 5058254619 
those sonographers will have a career-ending injury with resultant compensation claims [8]. Common musculoskeletal disorders caused by repeated ultrasound use include rotator cuff tendinitis, epicondylitis, carpal tunnel syndrome, hand-wrist tendinitis, and neck and back pain [8]. These complaints subsequently lead to decreased work efficiency, reduced quality of the health service, and psychological damage.

Ultrasonographers in Turkey is not included in the health system. Obstetric ultrasonography is performed by perinatologists, obstetricians, and radiologists. In Turkey, perinatologists spend most of their working hours using ultrasound during patient examination and actively use their upper extremities during the examination. Perinatologists usually sit or stand next to the patient during the examination and constantly use their abdominal semilunar transducers. Fetal anatomical scanning and fetal echocardiography examination represent valuable tools to detect congenital anomalies. To more ideally perform the ultrasound evaluation, perinatologists may need to force their extremities into unusual angles to accommodate maternal and fetal positions. Perinatologists actively use both upper extremities to wield the ultrasound probe and intervention materials for some invasive procedures. As technology becomes more advanced, the level of knowledge and the need for these procedures increase, so new studies are becoming more common worldwide.

In our clinical practice, we observed that upper extremity-related pathologies are common among perinatologists. From this observation, we decided to conduct a study to examine the relationship between upper extremity problems and the performance of abdominal sonography to provide an understanding of the prevalence of upper extremity pain among these physicians.

\section{METHODS}

This study was conducted as a prospective trial between June 2020 and August 2020. The online questionnaire prepared by the researchers was completed by volunteer perinatologists who participated. The study protocol was approved by the hospital's ethics committee and was registered with clinicaltrials.gov (NCT04477135). Signed informed consent was ob- tained from all participants before the start of the study.

Our study group consisted of perinatologists who work as subspecialists in perinatology in Turkey. Perinatologists who completed the questionnaire completely and were actively treating patients were included in the study. Perinatologists who had upper extremity discomfort before perinatology training, who received medical treatment for this reason, or who underwent an operation were excluded from the study. In Turkey, perinatology is positioned as a subbranch of gynecology and obstetrics. Gynecologists and obstetricians are entitled to become perinatology specialists after three years of perinatology training.

The questionnaire form included topics such as age, gender, years of perinatology specialist experience, average number of patients per week, minutes each patient's examination lasted, dominant hand, hand used to perform the ultrasound, and side of the patient from which the examination is performed. In addition to questions about demographic data, the following items were included in the questionnaire: Have you experienced upper extremity pain after starting perinatology? Have you had a radiological examination for this problem? Have you been diagnosed with a disease or any treatment you received? If there is pain, what are the frequency (every day, a few days a week, a few days a month, a few days a year) and the severity (rate it from 1 to 10)? Do you have neck pain? Have you been diagnosed with upper limb impingement syndrome? Do you do sports?

\section{Statistical Analysis}

SPSS 20 (IBM Corp. released 2011. IBM SPSS Statistics for Windows, version 20.0, Armonk, NY: IBM Corp.) was used to evaluate the data. The data were investigated using visual (histograms, probability plots) and analytical methods (Kolmogorov-Smirnov/ Shapiro-Wilk's tests) to determine their normal distribution. Differences between groups were evaluated using Student's t-test for parametric data and the Mann-Whitney U-test for non-parametric data. Relationships between categorical variables were analyzed using a chi-squared test. Bivariate correlations were investigated using Spearman's correlation analysis. A $p$ - value $<0.05$ was considered to indicate statistical significance. 


\section{RESULTS}

Overall, 115 perinatologists participated in this research. When the whole sample was evaluated, $48.6 \%$ $(\mathrm{n}=56)$ of the participants were women, and $51.4 \%$ $(\mathrm{n}=59)$ were men. Of all participants, $82(71.3 \%)$ had upper extremity pain, and $33(28.7 \%)$ had no upper extremity pain. In our study population, perinatologists with upper extremity pain were assigned to group 1. Group 2 comprised those who had no upper extremity pain. Patients in group 1 were divided into two subgroups according to pain intensity. The upper extremity pain intensity of the patients in subgroup A was four or less, and the pain intensity of the patients in subgroup B was five or greater.

A comparison of the demographic and occupa- tional characteristics of perinatologists with and without upper extremity pain is provided in Table 1. Participants in group 1 were perinatologists for six years (range, 1-23 years); those in group 2 offered perinatology services for four years (range, $1-8$ years; $p=$ $0.01)$. Eighty perinatologists $(97.6 \%)$ in group $1 \mathrm{had}$ dominant right hands compared with $33(100 \%)$ in group $2(p<0.001)$. The right hand was used to hold the ultrasound probe for 78 providers $(95.1 \%)$ in group 1 and 30 providers $(90.9 \%)$ in group $2(p<0.001)$. Eighty-two perinatologists $(100 \%)$ performed ultrasounds from the right side in group 1 compared with $30(90.9 \%)$ in group $2(p<0.001)$. No significant relationship was observed for age, gender, the average number of ultrasound examinations per day, or time allotted for each patient's examination between the two

\section{Table 1. Demographic and occupational characteristics of perinatologists with and without upper} extremity pain

\begin{tabular}{|c|c|c|c|c|}
\hline & $\begin{array}{l}\text { Total cohort } \\
\quad(n=115)\end{array}$ & $\begin{array}{l}\text { Upper extremity } \\
\text { pain present } \\
(n=82)\end{array}$ & $\begin{array}{l}\text { Upper extremity } \\
\text { pain absent } \\
(n=33)\end{array}$ & $p$ value \\
\hline Age (years) & $40(29-65)$ & $39.5(29-53)$ & $41(31-65)$ & $0.102^{\mathrm{a}}$ \\
\hline $\begin{array}{l}\text { Number of years performing as } \\
\text { a perinatologist }\end{array}$ & $6(1-23)$ & $6(1-23)$ & $4(1-8)$ & $0.01^{\mathrm{a}}$ \\
\hline Gender, n (\%) & & & & $0.780^{\mathrm{b}}$ \\
\hline Female & $56(48.7)$ & $46(56.1)$ & $10(30.3)$ & \\
\hline Male & $59(51.3)$ & $36(43.9)$ & $23(69.7)$ & \\
\hline $\begin{array}{l}\text { Distribution of ultrasound } \\
\text { examination per week }\end{array}$ & $100(5-1000)$ & $100(5-1000)$ & $80(30-150)$ & $0.184^{\mathrm{a}}$ \\
\hline $\begin{array}{l}\text { Time allotted for each patient's } \\
\text { examination (min) }\end{array}$ & $16(5-40)$ & $20(5-40)$ & $15(5-30)$ & $0.198^{\mathrm{a}}$ \\
\hline Dominant hand, $\mathrm{n}(\%)$ & & & & $<0.001^{b}$ \\
\hline Right & $113(98.3)$ & $80(97.6)$ & $33(100)$ & \\
\hline Left & $2(1.7)$ & $2(2.4)$ & 0 & \\
\hline $\begin{array}{l}\text { Hand holding the ultrasound } \\
\text { probe, } n(\%)\end{array}$ & & & & $<0.001^{\mathrm{b}}$ \\
\hline Right & $108(93.9)$ & $78(95.1)$ & $30(90.9)$ & \\
\hline Left & $7(6.1)$ & $4(4.9)$ & $3(9.1)$ & \\
\hline $\begin{array}{l}\text { Side that the perinatologist } \\
\text { perform ultrasound, } \mathrm{n}(\%)\end{array}$ & & & & $<0.001^{\text {b }}$ \\
\hline Right & $112(97.4)$ & $82(100)$ & $30(90.9)$ & \\
\hline Left & $3(2.6)$ & 0 & $3(9.1)$ & \\
\hline
\end{tabular}

Data are presented as median (minimum-maximum) or $n(\%)$.

aann-Whitney U test

${ }^{\mathrm{b}}$ Chi-square test 


\section{Table 2. Distribution the investigated parameters among the perinatologists experiencing upper} extremity pain

\begin{tabular}{|cc}
\hline Parameters & Data \\
\hline Radiological imaging, $\mathrm{n}(\%)$ & $12(14.6)$ \\
\hline Yes & $70(85.4)$ \\
\hline No & \\
\hline Medical treatment, $\mathrm{n}(\%)$ & $20(24.4)$ \\
\hline Yes & $62(75.6)$ \\
\hline No & $4.73 \pm 1.58$ \\
\hline Pain intensity (number \pm SD) & \\
\hline Frequency of pain, $\mathrm{n}(\%)$ & $10(12.2)$ \\
\hline Every day & $22(26.8)$ \\
\hline A few days per week & $44(53.7)$ \\
\hline A few days per month & $6(7.3)$ \\
\hline A few days per year & \\
\hline Work interruption, $\mathrm{n}(\%)$ & $10(12.2)$ \\
\hline Yes & $72(87.8)$ \\
\hline No & \\
\hline Nerve impingement syndrome, $\mathrm{n}(\%)$ & $14(17.1)$ \\
\hline Yes & $68(82.9)$ \\
\hline No & $52(63.4)$ \\
\hline Neck pain, $\mathrm{n}(\%)$ & $30(36.6)$ \\
\hline No & \\
\hline No & $30(36.6)$ \\
\hline
\end{tabular}

Data are presented as mean $\pm \mathrm{SD}$ or $\mathrm{n}(\%)$.

groups.

Table 2 summarizes the distribution of the investigated parameters among the perinatologists experiencing upper extremity pain. Seventy percent of participants with upper extremity pain did not have an examination, and $75.6 \%$ did not receive any treatment. The mean pain severity, ranked from a maximum severity value of 8 , was $4.73 \pm 1.58$. Overall, $12.2 \%$ of perinatologists with upper extremity pain noted pain every day; $26.8 \%$, a few days a week; $53.7 \%$, a few days a month; and $7.3 \%$, a few days a year. Only ten perinatologists $(12.2 \%)$ had to take a break because of pain; $52(63.4 \%)$ participants reported neck pain as well. In addition, $85.7 \%$ of orthopedics with LBP practiced sports.

Perinatologists with upper extremity pain were divided into subgroups according to pain severity and evaluated (Table 3 ). The mean age was $37.82 \pm 4.7$ years in group 1A and was $39.61 \pm 4.9$ years in group 1B $(p=0.098)$. Providers performed perinatology services for 5 years (range, 1-23) in subgroup 1A and for 7 years (range, 1-23) in subgroup 1B $(p=0.02)$. In group 1A, two perinatologists $(5 \%)$ reported pain every day, and eight $(20 \%)$ reported pain a few days a week. In group 1B, eight (19\%) reported daily pain, and $14(33.3 \%)$ reported pain a few days a week $(p<$ 
Table 3. Demographic and occupational characteristics of perinatologists through the upper extremity pain intensity

\begin{tabular}{|c|c|c|c|}
\hline & $\begin{array}{l}\text { The upper extremity } \\
\text { pain intensity } 4 \text { or less } \\
(n=40)\end{array}$ & $\begin{array}{l}\text { The upper extremity } \\
\text { pain intensity } 5 \text { and } \\
\text { above } \\
(n=42)\end{array}$ & $p$ value \\
\hline Age (years) (mean \pm SD) & $37.82 \pm 4.7$ & $39.61 \pm 4.9$ & $0.098^{\mathrm{c}}$ \\
\hline $\begin{array}{l}\text { Number of years performing as a } \\
\text { perinatologist (years) }\end{array}$ & $5(1-23)$ & $7(1-23)$ & $0.02^{\mathrm{a}}$ \\
\hline $\begin{array}{l}\text { Distribution of ultrasound } \\
\text { examination per week }\end{array}$ & $120(5-1000)$ & $100(25-350)$ & $0.126^{\mathrm{a}}$ \\
\hline $\begin{array}{l}\text { Time allotted for each patient's } \\
\text { examination (min) }\end{array}$ & $18(10-40)$ & $20(5-40)$ & $0.181^{\mathrm{a}}$ \\
\hline $\begin{array}{l}\text { Frequency of upper extremity } \\
\text { pain, } n(\%)\end{array}$ & & & $<0.001^{b}$ \\
\hline Every day & $2(5)$ & $8(19)$ & \\
\hline A few days per week & $8(20)$ & $14(33.3)$ & \\
\hline A few days per month & $26(65)$ & $18(42.9)$ & \\
\hline A few days per year & $4(10)$ & $2(4.8)$ & \\
\hline Gender, n (\%) & & & $0.269^{b}$ \\
\hline Female & $24(60)$ & $22(52.4)$ & \\
\hline Male & $16(40)$ & $20(47.6)$ & \\
\hline Sport, n (\%) & & & $0.534^{\mathrm{b}}$ \\
\hline Yes & $16(40)$ & $14(33.3)$ & \\
\hline No & $24(60)$ & $28(66.7)$ & \\
\hline
\end{tabular}

Data presented as median (minimum-maximum), $\mathrm{n}(\%)$ or mean $\pm \mathrm{SD}$.

aMann-Whitney U test

${ }^{\mathrm{b}}$ Chi-square test

'Student T test

Table 4. Correlation of (age, number of years performing as a perinatologist, average number of ultrasound examination per day, time allotted for each patient's examination, spor) some parameters and upper extremity pain

\begin{tabular}{lcc}
\hline & Upper extremity pain & \\
\hline Age & $\mathrm{R}$ & $p$ \\
\hline Number of years performing as a perinatologist & -0.153 & 0.102 \\
Average number of ultrasound examination per week & $\mathbf{0 . 3 2 0}$ & $<\mathbf{0 . 0 0 1}$ \\
Time allotted for each patient's examination & 0.124 & 0.185 \\
Sport & 0.120 & 0.200 \\
\hline
\end{tabular}

$P$ value $<0.05$ was statistically significant. 
0.001). No other parameters differed significantly between the two groups. As shown in Table 4, the number of years performing as a perinatologist was weakly associated with upper extremity pain.

\section{DISCUSSION}

The results of this study were obtained from an online survey of physicians working as perinatologists in Turkey. According to the results of this study, $71 \%$ of perinatologists have upper extremity pain, and this pain is often accompanied by neck pain. Participants with pain have been working as perinatologists for many years, and most do not play sports. Perinatologists with pain severity of 5 or more were older. In addition, people who worked as perinatologists for long periods had pain every day or a few days a week.

Upper extremity and neck pain can be caused by many reasons related to the use of ultrasound (e.g., posture disorder, use of ultrasound without warming movements, wrong probe grip). Repetitive strain injury may actually be the upper headline for ultrasound use and subsequent upper extremity pain [8]. Burnage [9] emphasized that inadequate preparation may cause muscle injury. In a study of Swedish dental personnel by Lindegard et al. [10], the prevalence of neck/shoulder pain was 56\%. Simonsen et al. [11] reported a $61 \%$ pain prevalence for beginning sonographers-higher than the existing literature. In addition, among sonographers who did not report neck/shoulder pain at baseline, $35 \%$ did so at follow-up after 2.5 years. In our study, the results were similar to the existing literature: $71 \%$ of perinatologists who participated had upper extremity pain. However, we focused on a group with ultrasound experience. The use of ultrasonography has a wide place in obstetrics education. Therefore, we can say that the prevalence of pain related to ultrasound use was higher in our study than in the literature. A survey of Canadian and American sonographers $(\mathrm{n}=$ $1,621)$ reported pain or discomfort in the neck $(74 \%)$, shoulder (76\%), upper back (58\%), upper arm (38\%), forearm (31\%), wrist (59\%), and hand/fingers (55\%) [12]. Unfortunately, because we did not classify locations of upper extremity pain in our study, we cannot mention specific regions.

In a study involving participants from different professions, the number of years that the operator spent scanning did not result in significant pain differences [8]. However, the study demonstrated a positive correlation between the prevalence of symptoms experienced and the number of days worked in ultrasound per week. In our study, participants with upper extremity pain had been working as subspecialists for a longer time than participants without pain. Perinatologists only perform high-risk pregnancy examinations and examine each patient with an abdominal ultrasound. Obstetricians may not be negatively affected by the use of abdominal ultrasounds, as they also perform gynecological ultrasounds and operations. That is, general gynecologists and obstetricians work in different positions during the day, unlike perinatologists, who constantly work in the same position. The variety of work positions may create a natural break. Therefore, we believe that perinatologists are a more accurate population than other branches to explore the relationship between abdominal ultrasound use and upper extremity pain.

In our study, the distribution of ultrasound examinations per week and the time allotted for each patient's examination was not statistically associated with the presence of pain. However, the pain was reported more often as these variables increased. If a physician who examines many patients does various warming movements or works with breaks between examinations, or if the physician is holding the probe with a correct posture by sitting in a more comfortable seat, there may be no upper extremity pain. We attributed the weak relationship between the years of working as a perinatologist and the presence of upper extremity pain to this bias $(\mathrm{r}=0.320, p<0.001)$. Most perinatologists participating in our study used their right hands and performed ultrasound by standing on the right sides of the patients. The physicians standing on the right sides versus those on the left sides had more upper extremity pain. This result may represent sampling bias because the left-handed cohort was very small. In a similar study, no significant difference was found between right and left-hand use [8].

Unlike other studies, most of the physicians with upper extremity pain did not have any examinations, did not take a break from work, did not receive any medical treatment, and did not experience nerve compression syndrome. We attributed these results to the severity of pain at a tolerable level $(4.73 \pm 1.58)$ and to the frequency of most pain a few days a month. No- 
tably, $63.4 \%$ of the patients with upper extremity pain had neck pain and did not exercise. During the use of ultrasound, pain, stiffness, or contractions may occur over time in the shoulder and neck muscles that work in correlation with the upper extremity. If these symptoms persist, they predispose to neck problems, such as cervical discopathy, cervical flattening, and arthritis. In addition, intensive wrist use can cause entrapment neuropathy, tendonitis, bursitis, and arthritis [12].

When we subgrouped the participants in our study according to pain intensity, we found that the pain intensity of the physicians who were older and who had worked as perinatologists for many years was greater than five and was more frequent. The perception of pain may increase with age, or people's awareness of pain may increase with age. In addition, pain severity is an objective assessment. Limitations of the survey itself include limited validity, errors resulting from non-response, and potential bias by motivation, honesty, and memory.

Among the strengths of the study was the focus on a specific group using ultrasound repeatedly in patients-namely, perinatologists. Many studies have conducted extremity pain and ultrasound, but we found no previous studies questioning the perinatologists' upper extremity pain. Our analysis showed a correlation between the presence of upper extremity pain and the years spent as a perinatologist.

\section{Limitations}

Our study has some limitations. First, we had a small number of participants, and breaks between patients were not assessed. Second, our study was not designed to investigate the posture of the participating physician while performing ultrasounds. Physicians whose back, shoulder, arm, and wrist positions were incorrect and who did not take care to use the correct posture while working may have introduced bias into the results. In addition, the type of ultrasound examination performed was not assessed. Some literature emphasizes that ultrasound type is an independent risk factor for joint pain [13]. Because our study was a nationwide survey, it was difficult to determine ultrasound types or standardize a review of the types. Moreover, depictions of own pain are different with each person.

\section{CONCLUSION}

Upper extremity pain caused by intensive ultrasound use is common in perinatologists; as the years in the profession increase, the frequency and severity of these pains may increase. In our study, demographic characteristics and patient-based risk factors were not significant in the prevalence of upper extremity pain. In this sense, personal factors, such as exercising with the correct posture, taking breaks at appropriate intervals, adjusting the lighting of the examination room, or doing sports to strengthen the upper extremity muscles, may be more meaningful. As suggested in the book "Work-related Upper Limb Disorder: A Sonographer's Survival Guide," musculoskeletal problems can be prevented by doing some warming movements. More comprehensive studies are needed to clarify the risk factors of upper extremity pain associated with professional ultrasound use in perinatologists to develop prevention strategies and investigate our recommendations' effectiveness.

\section{Authors' Contribution}

Study Conception: AEY; Study Design: AEY; Supervision: AEY, FE; Funding: N/A; Materials: N/A; Data Collection and/or Processing: AEY, FE; Statistical Analysis and/or Data Interpretation: AEY; Literature Review: FE; Manuscript Preparation: AEY and Critical Review: FE.

\section{Conflict of interest}

The authors disclosed no conflict of interest during the preparation or publication of this manuscript.

\section{Financing}

The authors disclosed that they did not receive any grant during conduction or writing of this study.

\section{REFERENCES}

1. Niu S. Ergonomics and occupational safety and health: an ILO perspective. Appl Ergon 2010;41:744-53.

2. Kaplama ME, Ak S, Yukkaldiran A. Is rhinoplasty surgery a risk factor for low back pain among otorhinolaryngologists? Facial Plast Surg 2021;37:102-6.

3. Gerr F, Letz R, Landrigan PJ. Upper-extremity musculoskeletal disorders of occupational origin. Annu Rev Public Health 1991;12:543-66. 
4. Bongers PM, Kremer AM, ter Laak J. Are psychosocial factors, risk factors for symptoms and signs of the shoulder, elbow, or hand/wrist?: A review of the epidemiological literature. Am J Ind Med 2002;41:315-42.

5. Musculoskeletal Disorders and the Workplace: Low Back and Upper Extremities. Panel on Musculoskeletal Disorders and the Workplace, Commission on Behavioral and Social Sciences and Education, National Research Council and Institute of Medicine. Washington DC: National Academy Press; 2001: pp. 429.

6. Reger MA, Welsh RK, Watson GS, Cholerton B, Baker LD, Craft $\mathrm{S}$. The relationship between neuropsychological functioning and driving ability in dementia: a meta-analysis. Neuropsychology 2004;18:85-93.

7. Bongers PM, de Winter CR, Kompier MA, Hildebrandt VH. Psychosocial factors at work and musculoskeletal disease. Scand J Work Environ Health 1993;19:297-312.

8. Janga D, Akinfenwa O. Work-related repetitive strain injuries amongst obstetric and gynecological ultrasound practitioners worldwide. Arch Gynecol Obstet 2012;286:353-6.

9. Burnage J. Work-related upper limb disorder: a sonographer's survival guide. Ultrasound 2007;15:38-42.

10. Lindegård A, Nordander C, Jacobsson H, Arvidsson I. Opting to wear prismatic spectacles was associated with reduced neck pain in dental personnel: a longitudinal cohort study. BMC Musculoskelet Disord 2016;17:347.

11. Gremark Simonsen J, Axmon A, Nordander C, Arvidsson I. Neck and upper extremity pain in sonographers - a longitudinal study. BMC Musculoskelet Disord 2020;21:156.

12. Azar FM, Canale ST, Beaty JH. Campbell's Operative Orthopaedics. 4-volume set, 13th ed., Elsevier; 2016.

13. Hackmon R, Sheiner E, Barnhard Y, Beer R, Meizner I. The hazards to practitioners of obstetric and gynecological ultrasound. Ultrasound Obstet Gynecol 2006;28:204-6. 